Trab. Ling. Aplic., Campinas, 50(1): 97-118, Jan./Jun. 2011

\title{
DISCURSO SOBRE LITERATURAS DE LÍNGUA INGLESA: UMA ANÁLISE BASEADA EM FERRAMENTAS DA LINGUÍSTICA DE CORPUS
}

\author{
DISCOURSE ON LITERATURE IN ENGLISH: AN ANALYSIS BASED ON \\ CORPUS-LINGUISTIC TOOLS
}

\author{
DANIELLE DE ALMEIDA MENEZES*
}

\begin{abstract}
RESUMO: Este artigo analisa o discurso de professores universitários de literaturas de língua inglesa, a fim de identificar como estes caracterizam seu discurso sobre literatura e ensino, com base em ferramentas computacionais. Para tanto, a fim de direcionar a análise de dados, recorre-se às noções de linguagem e discurso, em uma perspectiva dialógico-sistêmico-funcional, bem como a uma visão de análise do discurso enquanto atividade multidisciplinar (BAKHTIN, 1979 [1930]; 2006 [1979]; CHOULIARAKI e FAIRCLOUGH, 2001; FAIRCLOUGH, 2001; HALLIDAY, 1994). A geração dos dados se deu a partir de entrevistas semiestruturadas com dez professores de instituições de ensino superior, públicas e privadas, localizadas em diferentes partes da cidade do Rio de Janeiro. Essas entrevistas são analisadas qualitativamente com a ajuda de ferramentas da linguística de corpus (BERBER SARDINHA, 2004; OLIVEIRA, 2009; TOGNINI-BONELLI, 2001; VIANA, 2008). Tendo por base as linhas de concordância geradas para palavras-chave encontradas por meio do programa WordSmith Tools (SCOTT, 1999) para cada entrevista, foi possível perceber que cinco dimensões parecem caracterizar o discurso dos participantes: ontológica, metodológica, institucional, cognitiva e sócio-histórica. Entre as implicações desse estudo para o conhecimento científico, aponta-se a real necessidade de se investigar questões relacionadas à sala de aula de literatura, seguindo uma tradição já amplamente praticada por professores de língua (cf. RAJAGOPALAN, 2001; JORDÃO, 2004; PAIVA, 2005; GIEVE e MILLER, 2006; MICCOLI, 2007).
\end{abstract}

Palavras-chave: professores universitários de literaturas de língua inglesa; discursos; ferramentas computacionais.

\begin{abstract}
This article analyzes the discourse of university teachers of literature in English in order to identify how they characterize their discourse about literature and teaching, based on computational tools. To this end, in order to guide the data analysis, the study resorts to the notions of language and discourse, from a dialogic and systemic-functional perspective, as well as the view of discourse analysis as a multidisciplinary activity (BAKHTIN, 1979 [1930]; 2006 [1979]; CHOULIARAKI and FAIRCLOUGH, 2001; FAIRCLOUGH, 2001; HALLIDAY, 1994). The data for the present research were generated by means of semi-structured interviews with ten university teachers of public and private institutions from different districts in the city of Rio de Janeiro. These interviews are qualitatively analyzed with the support of corpus-linguistic tools (BERBER SARDINHA, 2004; OLIVEIRA, 2009; TOGNINI-BONELLI, 2001; VIANA, 2008). Based on concordance lines generated for the keywords found by means of the software WordSmith Tools (SCOTT, 1999) for each interview, it was possible to notice that five dimensions seem to characterize the participants' discourse: ontological, methodological, institutional, cognitive and socio-historical. Among the implications of this study to scientific knowledge is the real need to investigate issues related to the literature classroom, following a tradition which is commonly implemented by language teachers (cf. RAJAGOPALAN, 2001; JORDÃO, 2004; PAIVA, 2005; GIEVE E MILLER, 2006; MICCOLI, 2007).
\end{abstract}

Keywords: university teachers of literature in English; discourses; computational tools.

\footnotetext{
*UFRJ, Rio de Janeiro (RJ), Brasil. danielle.menezes1981@gmail.com
} 


\section{INTRODUÇÃO}

As literaturas de língua inglesa no Brasil se inserem em uma complexa realidade de ensino superior. Aliado ao fato de a cultura universitária ser algo relativamente recente em nosso país (SÁ CAMPOS, 1987), o desenvolvimento e a visibilidade dessas literaturas sempre estiveram ligados ao ensino de língua (ZYNGIER, 2003). Contudo, apesar da existência de todo um arcabouço metodológico desenvolvido internacionalmente para o ensino de língua inglesa (RICHARDS e RODGERS, 2001), que influencia diretamente a organização do ensino superior brasileiro, escasso tem sido o interesse em conhecer como metodologicamente se organiza o ensino das literaturas nesse idioma no Brasil. Não faltam referências sobre investigações acerca das salas de aula de língua (cf. RAJAGOPALAN, 2001A; 2001B; GRIGOLETTO, 2001; KEYS, 2001; JORGE, 2001; JORDÃO, 2004; PAIVA, 2005; GIEVE e MILLER, 2006; MICCOLI, 2007, para citar um número extremamente reduzido!), mas, em se tratando do ensino de literaturas de língua inglesa, pelo menos no Brasil, o que se percebe é que existem apenas esforços isolados (ZYNGIER, 2006; MENEZES e ZYNGIER, 2009).

Além da escassez de investigação empírica sobre a área, as literaturas em inglês sofrem as consequências de um ensino deficitário, fragmentário e segregacionista em todos os níveis da educação. Pensando especificamente nos cursos de Letras, responsáveis por oferecer o ensino de literaturas de língua inglesa, foco desse trabalho, o que se tem é uma vasta oferta ${ }^{1}$ : há faculdades isoladas, faculdades integradas, centros universitários, universidades públicas e particulares espalhadas pelos diferentes estados nacionais. Como os objetivos das instituições variam conforme a sua natureza, os profissionais formados nelas, consequentemente, apresentam também perfis diferentes.

Foi essa diferença no perfil de alunos de cursos de Letras que oferecem habilitação em língua inglesa que despertou o interesse pelo presente estudo. Enquanto professora de literaturas de língua inglesa, tive a oportunidade de contrastar minha realidade de formação, uma universidade pública federal, com minha realidade docente em duas faculdades particulares localizadas na zona oeste da cidade do Rio de Janeiro, região de periferia.

Por compartilhar da ideia de Lévinas 1993 [1972], de que o outro é a condição mesma da existência e, por isso, para que nos conheçamos melhor há necessidade de conhecer a alteridade, decidi analisar o discurso sobre literatura e ensino de dez professores universitários de literaturas de língua inglesa. A motivação para o estudo residia em uma melhor compreensão da realidade profissional em que havia sido inserida. Um dos objetivos investigativos ${ }^{2}$ era conhecer a função, ou funções, das escolhas linguísticas utilizadas na caracterização do discurso profissional desses professores.

Para que esse objetivo fosse alcançado, lancei mão de ferramentas computacionais oriundas da linguística de corpus (BERBER SARDINHA, 2004; THOMPSON e HUNSTON, 2006; TOGNINI-BONELLI, 2001; OLIVEIRA, 2009), a fim de perceber

\footnotetext{
${ }^{1}$ A oferta tem sido maior que a procura. Na cidade do Rio de Janeiro, por exemplo, conhecidas instituições, como a Universidade Gama Filho, fecharam os cursos de Letras por falta de alunos.

${ }^{2}$ Este artigo é resultado de parte da minha tese de doutorado, defendida em março de 2010, sob a orientação da Profa. Dra. Lúcia Pacheco de Oliveira, na Pontifícia Universidade Católica do Rio de Janeiro. 
o que sobressaía na fala de cada participante e como essas especificidades poderiam ser articuladas para caracterizar o discurso dos professores como um todo.

A escolha por realizar análise do discurso relaciona-se a minha compreensão de linguagem como um fenômeno social, dialógico, fruto da interação entre os sujeitos numa situação comunicativa, e de discurso como uma forma de agir sobre o mundo pelo fato de o mesmo estar imbuído de valores ideológicos (BAKHTIN, 1979 [1930], 2006 [1979]; FAIRCLOUGH, 2001). Adicionalmente, percebo a linguagem como um sistema semiótico em que sua dimensão social é tecida na estrutura gramatical da língua. Dessa forma, as escolhas dos falantes não podem ser compreendidas como aleatórias ou arbitrárias, mas fruto de intenções discursivas (HALLIDAY e HASAN, 1989; HALLIDAY, 1994). Assim, somente por meio da análise empírica de textos reais, ou seja, da língua em uso, é possível acessar crenças e valores dos falantes, percebendo como os mesmos agem discursivamente (TOGNINI-BONELLI, 2001; OLIVEIRA, 2009).

A opção por entrevistas semiestruturadas como instrumento para coleta dos dados alinha-se a essas perspectivas acerca de linguagem e discurso. Entrevistas, então, são compreendidas aqui como trocas dialógicas em que o significado é construído a partir da interação entre o entrevistado e o entrevistador (ROLLEMBERG, 2008).

Esses pressupostos permitem compreender a natureza do estudo. Nas próximas seções, aprofundamos a discussão, a fim de mostrar a viabilidade de se lançar mão de recursos da abordagem de corpus para realizar análise do discurso. Por fim, apresentamos os resultados obtidos e suas considerações finais.

\section{A ABORDAGEM DE CORPUS EM ANÁLISE DO DISCURSO}

Fairclough (2001) apresenta a área da análise do discurso como uma atividade multidisciplinar, deixando claro que não existe procedimento fixo para se fazer a análise. Segundo o autor, as pessoas abordam a análise do discurso de formas distintas, de acordo com a visão que possuem de discurso e com a natureza do trabalho. Portanto, por não haver diretrizes restritivas no tocante à metodologia empregada, o pesquisador que analisa o discurso tem maior liberdade para escolher a forma de prospecção dos dados que mais se afina com suas convicções investigativas.

Pensando especificamente acerca dos estudos da linguagem, observa-se que os mesmos podem ser divididos em duas áreas principais: os que estão voltados para as estruturas e aqueles acerca dos usos, conforme sugerem Biber, Conrad e Reppen (1998). Tradicionalmente, conforme apontam os autores, a análise linguística parte de considerações abstratas sobre a língua sem a sua observação efetiva, enfatizando a identificação de unidades estruturais e de classes (morfemas, palavras, sintagmas, classes gramaticais) e a descrição de unidades menores que podem ser combinadas com outras maiores (como vocábulos que se combinam e formam sintagmas, que, por sua vez, se combinam e formam orações etc.). Todavia, há também uma perspectiva diferente, a qual enfatiza a língua em uso, ou seja, a maneira como ela concretamente se apresenta. Tal perspectiva é o fundamento básico da linguística de corpus, para a qual se faz possível e desejável investigar como uma língua é efetivamente utilizada por seus usuários. 
Assim como a Análise do Discurso, a Linguística de Corpus é uma área de cunho interdisciplinar e vê a linguagem como "um fenômeno social e analisada a partir de atos concretos de comunicação, isto é, textos reais, buscando o significado onde este é negociado, ou seja, no discurso" (OLIVEIRA, 2009, p. 49). Essa perspectiva sobre a linguagem e a maneira específica de fazer pesquisa através do estudo de textos reais, com o auxílio de programas computacionais, a fim de se extraírem evidências linguísticas, levam Oliveira (2009) a afirmar que a Linguística de Corpus é uma área do conhecimento com bases teóricas próprias e uma forma específica de desenvolver análises linguísticas. Acreditamos que o aporte metodológico da linguística de corpus pode favorecer o fazer empírico em Análise do Discurso.

Um leque de possibilidades de investigação se abre ao buscar estudar a língua em uso, pois tanto a compreensão de aspectos funcionais em uma língua como um todo quanto à compreensão e interpretação de textos individuais tornam-se viáveis. Os corpora, portanto, são coleções de textos produzidos em situações reais que são armazenadas e acessadas por meio de ferramentas computacionais a fim de serem estudadas de forma não linear, quantitativa e/ou qualitativamente (BERBER SARDINHA, 2004; BIBER, CONRAD e REPPEN, 1998; HUNSTON, 2005). Segundo Hunston (2005) os linguistas geralmente usam o termo corpus para descrever uma amostra de linguagem, que ocorre naturalmente, mas que foi coletada para estudos empíricos.

De acordo com Barlow (1996), o uso de computadores e corpora oferece ao pesquisador a possibilidade de controlar o acesso aos dados conforme seu interesse investigativo (através das diferentes ferramentas) de maneira precisa e confiável. Portanto, além da crença de que a linguagem deve ser estudada a partir de seu uso, nisto reside a abordagem de corpus nessa tese: o acesso aos dados torna-se mais organizado, sistematizado.

Essa forma de acessar a linguagem possibilita aos dados tratamento qualitativo e quantitativo, sendo de grande relevância quando se pensa a interface entre a Análise do Discurso e a Linguística de Corpus. CHOULIARAKI e FAIRCLOUGH (2001) afirmam que muito do trabalho até então realizado pela Análise do Discurso tem sido de cunho teórico e programático, priorizando métodos qualitativos, e que, dessa forma, tem recebido críticas por não realizar uma análise sistemática, que inclua o uso de métodos quantitativos e computacionais, os quais poderiam fornecer base linguística mais sólida aos apelos sociais acerca do discurso. Outra crítica à escolha metodológica comumente utilizada em Análise do Discurso refere-se à ausência de replicabilidade e objetividade (TRAPPESLOMAX, 2004). A análise baseada em corpus, portanto, minimiza essas contestações.

Não obstante, como Oliveira (2009, p. 50) coloca, a Linguística de Corpus não se restringe a resultados numéricos extraídos do corpus, pois números ou estatísticas não são suficientes para a descrição de fatos linguísticos, “já que, para interpretar os dados, com base no corpus, muitas vezes temos que levar também em conta o cotexto e os aspectos sócioculturais que estão ligados aos textos". A autora aponta ainda que tanto as evidências linguísticas quanto os números obtidos dos dados não são informações por si sós, sendo necessária a interpretação por parte do pesquisador a fim de que considerações e conclusões possam ser tecidas. Isso evidencia que a abordagem de corpus, aliada à Análise do Discurso, não suprime ou inviabiliza a subjetividade, ao contrário, reafirma-a, 
todavia, atribui maior sistematicidade e confiabilidade às análises (BAKER, 2004).

Há diferentes tipos de corpora. Hunston (2005) considera a existência de oito: corpus especializado, corpus geral, corpora comparáveis, corpora paralelos, corpus de aprendizes, corpus pedagógico, corpus diacrônico ou histórico e corpus monitor. Um corpus especializado, tipo o utilizado no presente estudo, serve para investigar um tipo particular de linguagem (HUNSTON, 2005). Aqui, o que se fez foi compilar um corpus especializado, a partir das entrevistas, para o estudo do discurso docente sobre literatura.

Para que a análise de corpora se torne viável, é imprescindível o uso de programas computacionais, como o Wordsmith Tools (SCOTT, 1999), ao qual recorremos. O programa possui várias ferramentas com as quais se torna possível extrair a informação linguística que se deseja investigar. As ferramentas utilizadas neste estudo são descritas a seguir.

\subsection{Ferramentas computacionais do estudo}

Dentre as ferramentas que o WordSmith (SCOTT, 1999) oferece, recorremos a três: WordList, KeyWords e Concord. A ferramenta WordList possibilita, nas palavras de Viana (2008, p. 135), "a geração de listas de todas as formas - ou seja, todas as palavras diferentes - que ocorrem em um único texto ou em grandes corpora até o limite de 8 milhões de entradas". As listas geradas podem ser apresentadas em ordem alfabética ou de frequência, dependendo dos objetivos do estudo. A figura abaixo ilustra a tela de geração de lista de palavras de um dos participantes:

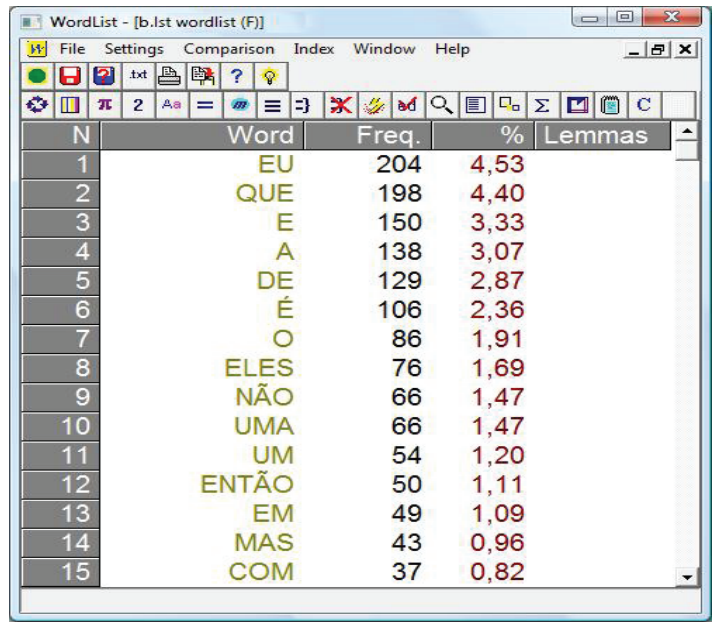

Figura 1 - Lista de palavras

Já a ferramenta KeyWords consiste em contrastar a lista de palavras de um corpus ou texto de pesquisa, aquele do qual se busca extrair informações, com a de um corpus de referência, que precisa ser maior que o de pesquisa (cf. BERBER SARDINHA, 2004). Por exemplo, para cada entrevista isolada (corpus de pesquisa), o programa gerou uma 
MENEZES - Discurso sobre literaturas de língua inglesa: uma análise baseada...

lista de palavras e para as demais entrevistas agrupadas (corpus de referência), outra lista. Desta maneira, foi possível comparar o que cada entrevista possuía de específico e, consequentemente, o que a diferenciava das demais. A figura abaixo apresenta uma tela gerada pela ferramenta:

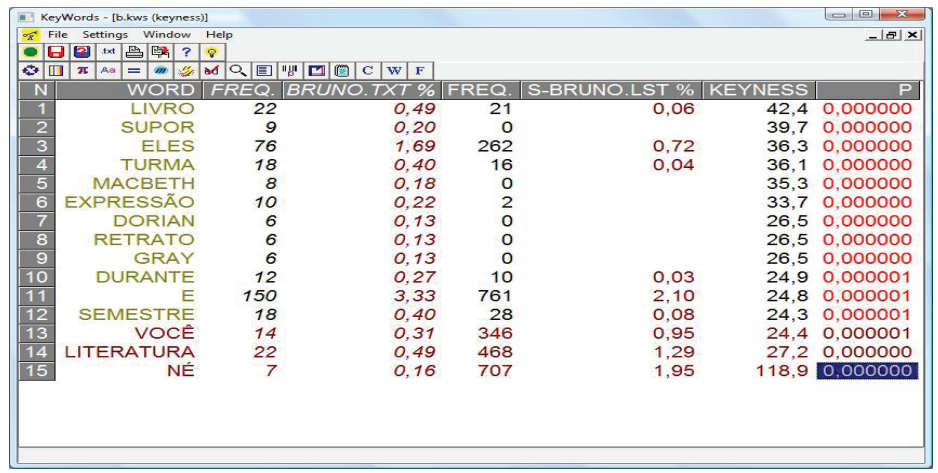

Figura 2 - Palavras-chave

Por fim, a ferramenta Concord possibilita ao pesquisador evidências linguísticas a serem analisadas de forma qualitativa. Grosso modo, a ferramenta gera listas que apresentam todas as ocorrências de uma palavra selecionada de um banco de dados, a node word, com um pequeno cotexto (contexto linguístico) ao redor. Neste estudo, foram geradas linhas de concordância para cada palavra-chave encontrada, com o objetivo de compreender sua relevância dentro da entrevista e entender por que ela fora considerada chave.

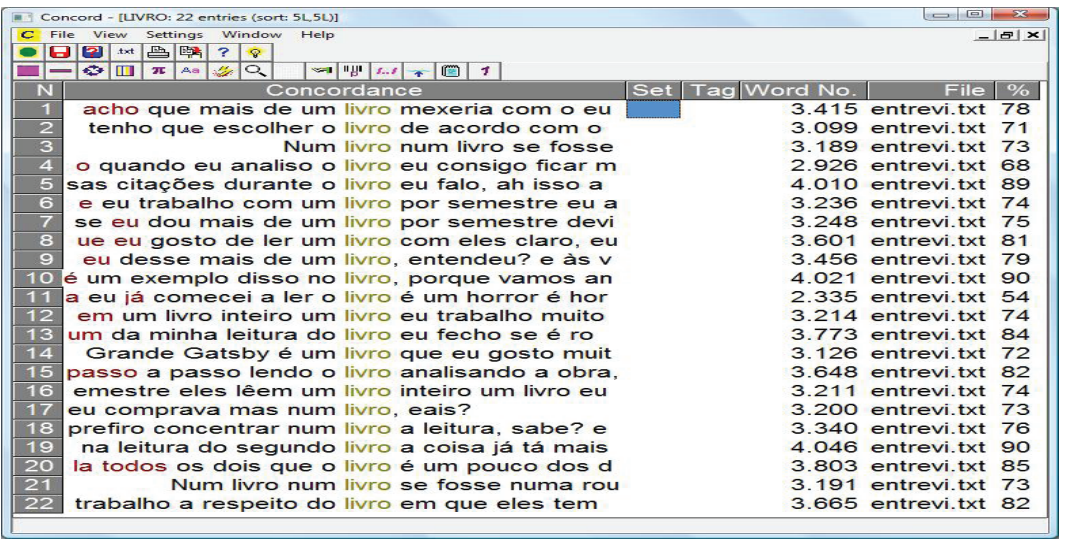

Figura 3 - Linhas de concordância

A utilização dessas três ferramentas permitiu que tentássemos sistematizar os achados em dimensões provisórias acerca do modo como o discurso dos participantes se organiza. Na próxima seção, apresentamos os procedimentos metodológicos do estudo. 


\section{PROCEDIMENTOS METODOLÓGICOS}

Entrevistas semiestruturadas foram escolhidas como instrumentos de geração de dados por permitirem que se tenha acesso a informação acerca das mais variadas questões, de foro mais íntimo, particular ou não (LÜDKE e ANDRÉ, 2001). Além disso, elas permitem correções, esclarecimentos e adaptações, realizando-se de maneira única com cada informante. As entrevistas realizadas para este estudo seguiram o seguinte roteiro:

\begin{tabular}{|c|c|}
\hline 1) & Formação do professor \\
\hline 2) & $\begin{array}{l}\text { Perfil enquanto professor: } \\
\text { - } \quad \text { Há quanto tempo leciona? } \\
\text { - } \quad \text { Professor exclusivo de literaturas de língua inglesa? } \\
\text { - } \quad \text { Onde trabalha? } \\
\text { - } \quad \text { Qual a carga horária das disciplinas ministradas? } \\
\text { - Quantas turmas possui? }\end{array}$ \\
\hline 3) & Definição de literatura (o que é literatura?) \\
\hline 4) & Qual a relevância do ensino/aprendizado de literaturas de língua inglesa? \\
\hline 5) & $\begin{array}{l}\text { Metodologia das aulas: } \\
\text { - Aulas em inglês ou português? } \\
\text { - Utilização de textos originais ou traduções? } \\
\text { - Como é a recepção das aulas? }\end{array}$ \\
\hline
\end{tabular}

\section{Quadro 1 - Roteiro das entrevistas}

Com o intuito de preservar a identidade dos professores, a eles foram dados nomes fictícios: Bernardo, Edna, Fátima, Letícia, Lúcio, Maria, Paula, Raquel, Rogério e Vânia. As entrevistas tiveram tempo médio de 30 minutos e ocorreram em locais escolhidos pelos participantes, entre setembro de 2007 e março de 2008. Os critérios adotados para a seleção dos docentes foram:

(a) Contexto de atuação - para contemplar diversificadas realidades de ensino, convidamos docentes atuantes em instituições públicas e particulares, localizadas em diferentes partes da cidade do Rio de Janeiro;

(b) Titulação - optamos por participantes mestres ou doutores;

(c) Experiência profissional - na época das entrevistas, os professores possuíam, no mínimo, um ano de experiência docente na área de literaturas de língua inglesa.

Como pretendíamos obter uma visão geral do conteúdo das entrevistas, decidimos utilizar ferramentas computacionais por acreditar que as mesmas são capazes de oferecer uma forma de prospecção dos dados um pouco mais sistemática ${ }^{3}$ e abrangente do que uma

${ }^{3}$ Reconhecemos que a subjetividade do pesquisador não pode ser excluída e é imprescindível para a atribuição de significado, ou seja, para a interpretação dos resultados obtidos por meio da utilização de ferramentas computacionais. 
análise de conteúdo usual. Se nosso interesse investigativo fosse outro, como a análise de questões específicas acerca de parte do conteúdo abordado pelas entrevistas, talvez os dados tivessem recebido tratamento diferente. Sendo assim, por causa de nossas escolhas metodológicas, após a geração dos dados sob a forma de entrevistas, as mesmas foram transcritas e convertidas para o formato TXT. Isso permitiu que pudessem ser analisadas como corpora linguísticos, com o auxílio das ferramentas do programa WordSmith Tools (Scott, 1999), descritas na seção anterior.

Inicialmente, foram geradas dez listas de palavras, uma para cada entrevista. Em seguida, produzimos outras dez. Cada uma dessas novas listas era composta por nove entrevistas. Por exemplo, a primeira lista contemplava as entrevistas de 2 a 10, a segunda, 1, 3-10, e assim por diante. As listas individuais foram comparadas com as listas formadas por nove entrevistas através da ferramenta KeyWords. De modo geral, esse procedimento permitiu conhecer as palavras-chave de cada lista individual a partir da comparação da mesma com outra lista formada pelas demais entrevistas. Como cada entrevista forma um corpus de estudo, podemos dizer que esta pesquisa lançou mão de dez corpora de estudo e de dez corpora de referência. Cada corpus de estudo conta, em média, com 4.596 palavras, enquanto cada corpus de referência possui, em média, 41.366 palavras.

Para compreender como as palavras-chave se comportam ao longo de cada entrevista, foram geradas linhas de concordância. A análise dessas linhas indica que as mesmas parecem exercer diferentes funções dentro das entrevistas. As palavras-chave, portanto, serviram apenas para dar o pontapé inicial, já que as funções percebidas são, na verdade, possibilidades de agrupamento das linhas de concordância geradas. Posteriormente, numa tentativa de sistematização do conteúdo global das interações a partir da interpretação de todas as linhas de concordância encontradas, conceituamos cinco dimensões do discurso dos participantes, que podem ser entendidas como provisórias, mas que nos ajudam a compor uma visão de como esse discurso sobre literatura e ensino pode ser caracterizado.

Antes de passar para a análise dos dados, cabe mencionar que há estudos no Brasil que também lançam mão da ferramenta de extração de palavras-chave a fim de investigar peculiaridades de determinados gêneros. A título de ilustração, citamos Gonçalves (2008, apud VIANA, V.; TAGNIN, S. 2011); Tagnin e Teixeira (2004, apud VIANA, V; TAGNIN, S. 2011); e Viana (2008).

\section{ANÁLISE DOS DADOS}

As principais funções encontradas para as linhas de concordância geradas para as palavras-chave foram nomeadas como: conceituação de literatura; caracterização de objetos; estabelecimento de nomenclaturas e referenciação; descrição da prática docente e posicionamento discursivo. Abaixo, apresentaremos nossas definições para as funções e exemplos para ilustrá-las. 
Função 1 - Conceituação de literatura: Fazem parte deste grupo as linhas de concordância que revelam, implícita ou explicitamente, visões de literatura:

\section{Bernardo:}

$$
\text { macbeth-dorian - retrato - gray - expressão }
$$

(1) /.../ eu vou demonstrando o caminho que Macbeth vai fazendo como herói trágico /.../

(2) /.../ fazendo-os perceber como às vezes as estratégias narrativas são utilizadas pelos escritores para atingir determinados objetivos, como, por exemplo, vamos supor, O Retrato de Dorian Gray é expressão e é uma crítica à Inglaterra Vitoriana /.../

(3) /.../ eu acredito que literatura seja expressão de uma cultura e não só uma expressão de uma cultura, mas de visões específicas /.../

(4) /.../ eu pude ver literatura como expressão da língua, mas com os meus alunos eu não consigo fazer isso a todo momento $/ . . . /$

\section{Lúcio:}

$$
\text { ela }
$$

(5) /.../ a literatura, ela é necessária, é necessária para a vida /...

\section{Maria:}

\section{escrito}

(6) /.../ Tudo que é escrito é literatura /.../

(7) /.../ a literatura é algo que foi escrito há 50 anos ou há séculos /.../

(8) $/$.../ pra me atrair ele [o texto literário] tem que ser bem escrito /.../

\section{Paula:}

\section{conhecimento}

(9) /.../ ela serve pra isso, pra dar a ele esse conhecimento maior /.../

\section{Rogério:}

$$
\text { arte-relevância }
$$

(10) /.../ o que a gente chama de arte, literatura, tudo isso, foi durante séculos privilégio da elite /.../

(11) /.../ Literatura é uma arte, é a arte cuja matéria é a linguagem /.../

(12) /.../ a relevância da literatura é a relevância da arte na vida /.../

(13) /.../ uma pergunta dessa, qual a relevância da literatura, né, acho que é a mesma coisa, qual é a relevância da arte? /..

(14) /.../ na cultura do dinheiro ela tem relevância como mercadoria /.../

(15) /.../ então, eu acho, assim, que a relevância é enorme da literatura /.../

Função 2 - Caracterização de objetos: Neste grupo, as linhas de concordância geradas para as palavras-chave encontradas caracterizam ou avaliam instituições, alunos, o trabalho docente etc.

\section{Fátima:}

\section{Legal}

(1) $/ . . . /$ acho até um trabalho legal pra fazer com os alunos /.../ 
MENEZES - Discurso sobre literaturas de língua inglesa: uma análise baseada...

(2) $/ \ldots /$ e é muito legal pra quem trabalha com isso, muito legal ler esses textos do Cândido /.../

(3) $/ . . . /$ é um tema super instrumentalizador pra você trabalhar, vir a trabalhar com literatura /.../ e é de uma forma mais legal, mais teórica, bacana /.../

\section{Letícia:}

\section{Graduação - norte-americana}

(4) /.../ esse conhecimento que eles adquirem das Literaturas de Língua Inglesa, que na nossa graduação é dividido em Literatura Inglesa e Literatura Americana /.../

(5) /.../ nós partimos na nossa graduação do pressuposto que o aluno já vem pra gente com conhecimento da língua /.../

(6) /.../ os alunos escrevem em inglês tanto na graduação, como na especialização e no mestrado /../

\section{Lúcio:}

\section{universidades - privadas}

(7) /.../ nas universidades privadas praticamente os alunos não têm aula de cultura Anglo-Americana /.../

(8) /.../ tem várias universidades privadas que não têm Literatura Inglesa e Norte-Americana /.../

(9) $/ \ldots /$ nas universidades privadas praticamente os alunos não têm aula de Cultura Anglo-Americana /.../

(10) /.../ eu dou aula em língua inglesa, né, nas universidades privadas você não consegue fazer isso integralmente /.../

(11) $/ . . . /$ mas ele consegue sair com um nível satisfatório /.../

\section{Paula:}

\section{conhecimento}

(12) /.../ então eu vejo como essa falta de conhecimento deixa para esses alunos um nível de superficialidade muito grande $/ . . . /$

(13) /.../ falta a eles um conhecimento cultural ou um conhecimento literário /.../

(14) /.../ então quando o aluno tem esse conhecimento, falta a eles possibilidades, né /.../

\section{Vânia:}

\section{nome da instituição ${ }^{4}$}

(15) /.../ a nossa carga horária no nome da instituição é muito pequena /.../

(16) /.../ o nosso currículo no nome da instituição ainda é bastante antiquado /.../

Função 3 - Estabelecimento de nomenclaturas e referenciação: Foram agrupadas aqui as linhas de concordância cujas palavras-chave nomeiam (disciplinas, cursos, instituições etc.) ou fazem referências discursivas:

\section{Bernardo:}

\section{Expressão - eles}

(1) /.../ São três disciplinas só, eh:: de literatura, Expressão Literária Britânica I e II e Expressão Literária Estado-Unidense /.../

(2) /.../ a demanda é pequena, eles não conseguem formar duas turmas /.../

${ }^{4}$ A fim de preservar a identidade de Vânia, não divulgaremos a palavra-chave encontrada, pois a mesma revela a instituição de origem da professora. 
(3) /.../ de uns tempos pra cá, eles passaram a dividir isso, então a primeira avaliação pode ser um trabalho e a segunda tem que ser necessariamente uma prova /.../

Edna:

$$
\text { nome da instituição }{ }^{5} \text { - aqui }
$$

(4) /.../ Eu dou aula aqui e dou aula na nome da instituição /.../

(5) $/$.../ Eu uso a mesma metodologia aqui e lá /.../

(6) Eh, aqui eu trabalho 20 horas...

(7) /.../ eu não consigo chegar até onde eu chego aqui, né? porque é uma faculdade particular /.../

(8) /.../ os currículos não privilegiam a literatura nas faculdades particulares, aqui também eu acho que não privilegia, embora haja um grande número de literatura /.../

\section{Letícia:}

\section{norte-americana}

(9) /.../ No setor de Literatura Norte-Americana nós somos apenas três professoras /.../

(10) /.../ o Curso de Cultura Norte-Americana I cobre do período de colonização até (...) mais ou menos o fim do século XIX /.../

\section{Lúcio:}

$$
\text { nome - ela }
$$

(11) /.../ só duas pessoas o professor Rogério e a professora Vânia, não é, como efetivos e todos os outros são contrato eu, Edna e o... esqueci o nome agora /.../

(12) /.../ Alias Grace, o nome do livro também é em função de um imigrante irlandês /.../

(13) /.../ o principal nome é Jasmine /.../

(14) $/$.../ ela escreve muito sobre a temática da imigração /.../

Maria:

ele

(15) /.../ The Catcher in the Rye que é a história de um rapaz que ele não consegue interagir com a sociedade I.../

(16) $/$.../ ele tem que tá bem escrito, ele tem que falar de temas que toquem a pessoa /.../

\section{Paula:}

\section{disciplina - disciplinas}

(17) /.../ no curso tem uma disciplina, Literatura Norte-Americana, que tem 80 horas /.../

(18) /.../ por exemplo, a disciplina de Métodos e Técnicas de Estudo é interessante /.../

\section{Rogério:}

arte

(19) /.../ tinha o Museu de Arte Moderna /.../

\section{Vânia:}

$$
\text { IV - nome da instituição }{ }^{6}
$$

${ }^{5} \mathrm{~A}$ fim de preservar a identidade de Edna, não divulgaremos a palavra-chave encontrada, pois a mesma revela a instituição de origem da professora. 
MENEZES - Discurso sobre literaturas de língua inglesa: uma análise baseada...

(20) /.../ a nossa carga horária no nome da instituição é muito pequena /.../

(21) /.../ o nosso currículo no nome da instituição ainda é bastante antiquado /.../

Função 4 - Descrição da prática docente: foram reunidas neste grupo as linhas de concordância em que percebemos descrições da prática, escolhas pedagógicas, avaliações / reflexões do que se pode fazer ou do que se faz em sala de aula, dentre fatores diversos concernentes à relação professor-aluno.

\section{Bernardo:}

$$
\text { livro-eles-durante-semestre }
$$

(1) /.../ eu destaco diversas citações durante o livro, eu falo, ah isso aqui é um exemplo disso

(2) /.../ o Grande Gatsby é um livro que eu gosto muito, só que na tradução brasileira custa cinquenta e três reais $/ . . . /$

(3) /.../ e eu trabalho com um livro por semestre, eu acho que se eu dou mais de um livro por semestre, devido à carga horária muito pequena, eu não conseguiria cumprir o programa /../

(4) /.../ porque eu acho que mais de um livro mexeria com o, eu diria o, eu não poderia aprofundar o que eu aprofundo /.../

(5) /.../ eu gosto de ler um livro com eles. Claro, eu não leio tudo com eles, mas fazendo uma leitura passo a passo, como a gente fazia, como pelo menos eu fiz na (nome da instituição)

(6) $/ . . . /$ eu peço que eles leiam e aí durante a aula leio o texto em inglês com eles /.../

(7) /.../ como eu dou muito contexto histórico durante as aulas /.../

(8) $/ \ldots /$ nas minhas disciplinas por semestre eles lêem um livro inteiro /.../

(9) /.../ se eles não conseguem a média, eles têm direito a fazer mais uma outra prova /.../

(10) /.../ durante a aula, leio o texto em inglês com eles e vou tentando analisar /.../

(11) /.../ nas minhas disciplinas por semestre eles lêem um livro inteiro /.../

(12) /.../ várias pessoas dessa última turma que leu Macbeth comigo disse, várias pessoas falaram, ah, Bernardo eu quero fazer a minha monografia sobre Shakespeare /.../

\section{Lúcio:}

universidades - consegue

(13) /.../ nas universidades públicas eu sempre dou as aulas em inglês /.../

(14) $/$.../ você até consegue num segundo momento optar pela língua inglesa /.../

(15) /.../ tem uma certa resistência, mas você consegue ultrapassar isso também /.../

(16) /.../ aqui, né, você já consegue fazer coisa, mais automaticamente /.../

(17) $/ . . . /$ nas universidades privadas, você não consegue fazer isso integralmente /.../

(18) /.../ nas públicas, você consegue trabalhar com um nível de qualidade melhor /.../

(19) /.../ um poema como Beowulf, que é um poema difícil /.../, os alunos têm uma certa resistência, mas você consegue ultrapassar isso também /.../

\section{Maria:}

the - baladas - rock - tube - you - rye - you - catcher - balada - raven - in

(1) /.../ a gente tá trabalhando com o The Crucible/.../

(2) /.../ ele escreveu um poema The Raven, que também é uma balada /.../

(3) /.../ a gente tá trabalhando no The Catcher in the Rye /.../

(4) /.../ o Texto e Leitura II então já seria o equivalente a uma Literature with the small ' l', né

(5) $/ . . . /$ eu vou da balada irlandesa até Alan Parker /.../

(6) $/ . . . /$ eu trabalhei várias baladas medievais interessantes /.../

${ }^{6} \mathrm{~A}$ fim de preservar a identidade de Vânia, não divulgaremos a palavra-chave encontrada, pois a mesma revela a instituição de origem da professora. 
(7) /.../ eu dei o rock pra eles na apresentação do Catcher in the Rye /.../

(8) /.../ um aluno trouxe aquele rock do Rolling Stones /.../

(9) /.../ eu procuro no You Tube essas baladas /.../

(10) /.../ a minha aula sem You Tube não funciona /.../

\section{Rogério:}

\section{drama}

(33) /.../ eu dou a parte de drama, que é o drama moderno, contemporâneo /.../

\section{Vânia:}

$$
\text { eles - dez - obrigados - colegas - seção }
$$

(34) $/ . . . /$ eu faço um trabalho muito intenso com os alunos pra eles perceberem que uma coisa não exclui a outra $/ . . . /$

(35) $/$.../ eu faço um método em que eles, que eles são obrigados a ler /.../

(36) $/ . . . /$ eles têm que fazer um report pro colega /.../

(37) $/ . . . /$ no começo do semestre eles ficam apavorados, mas depois eles ficam fascinados com aquele processo $/ . . . /$

(38) $/$.../ na frente dos colegas, então eles são obrigados a ler /.../

(39) $/$.../ eles começam a ver a opinião dos outros colegas /.../

(40) $/$.../ eu divido o romance em dez partes /.../

(41) /.../ não são dez capítulos são dez segmentos /.../

(42) /.../ então ele é dividido em dez segmentos de trinta páginas /.../

(43) $/$.../ cada seção eu tenho três ou quatro perguntas /.../

(44) /.../ eu escrevo no quadro seção A, B, C, D até a seção E /.../

(45) $/ . . . /$ todos os grupos são obrigados a ler as trinta páginas /.../

(46) /.../ são obrigados a ler, são obrigados, eles não têm como pegar isso na internet /.../

Função 5 - Posicionamento no discurso: As linhas de concordância geradas e aqui agrupadas têm a função de contribuir para que o professor se coloque no discurso, oferecendo sua opinião a respeito de diferentes questões: ensino (à distância), contraste entre a realidade contemporânea e outra época etc. Em alguns casos, como Fátima, a palavra-chave é o principal elemento para a classificação da linha nesta função.

\section{Fátima ${ }^{7}$ :}

$$
\text { acho }- \text { sei }
$$

(1) /.../ eu acho que vários professores trabalham assim, não acho que as pessoas só deem aula expositiva na (nome da instituição) /.../

(2) /.../ eu acho que a literatura é esse desejo da linguagem de produzir desejo no outro /.../

(3) $/ . . . /$ eu acho que a literatura é um lugar onde a linguagem se busca mais sedutora /.../

(4) /.../ trabalhar com literatura dá uma possibilidade de criação na sala de aula, de como você vai abordar um texto, o que você vai relevar de um texto, é eu acho que é uma coisa nesse sentido, uma coisa muito boa /.../

(5) /.../ eu sei que a linguagem para mim se mostrando /.../

(6) $/$.../ eu não sei dar o curso ou eu não aprendi ainda /.../

${ }^{7}$ Além de indicarem posicionamento no discurso, as linhas de concordância aqui apresentadas para Fátima marcam também suas crenças acerca do que seja literatura e sobre sua prática em sala de aula. 
MENEZES - Discurso sobre literaturas de língua inglesa: uma análise baseada...

\section{Letícia:}

\section{norte-americana}

(7) $/ \ldots /$ eu adoro literatura norte-americana /.../

\section{Lúcio:}

\section{distância}

(8) /.../ a filosofia do ensino à distância é ótima, não é? Mas só que está sendo deturpada e o ensino à distância vai ser uma coisa discriminada daqui a pouco, e os professores tão perdendo o emprego /.../

\section{Rogério:}

$$
\text { dia - tinha }
$$

(9) /.../ hoje em dia as pessoas desconstroem sem construir /.../

(10) /.../ a gente vive numa época muito mais pragmática hoje em dia /.../

(11) $/ \ldots /$ o problema que hoje em dia as coisas dão uma certa confusão /.../

(12) /.../ hoje em dia é tudo usado até, até livros que ensinam as pessoas a viver /.../

(13) /.../ hoje em dia a gente vive uma vida extensiva, a gente faz várias coisas durante o dia /.../

(14) /.../ essa coisa toda é discutível hoje em dia /.../

(15) $/$.../ você tinha uma efervescência cultural muito grande /.../

(16) $/ \ldots /$ na parte de teoria literária você tinha uma equipe muito boa /.../

(17) $/ \ldots /$ você tinha mais contato com pessoas de outros cursos /.../

(18) /.../ o teatro tinha também um pouco de poesia, né /.../

(19) /.../ tudo isso você tinha essas matérias da área de humanidade /.../

\subsection{As palavras-chave nos discursos: discussão}

Ao refletir sobre as palavras-chave e as respectivas linhas de concordância ${ }^{8}$ (vide seção anterior) encontradas para os participantes, chegamos a algumas considerações sobre o que há de peculiar no discurso profissional de cada docente.

Em se tratando de Bernardo, os dados mostram que o professor fala sempre de si, mesmo quando não faz uso de primeira pessoa. Frequentemente, sua experiência acadêmico-profissional permeia seu discurso, inclusive quando se tem palavras-chave que não fazem referência ao indivíduo, como durante. Dito de outra forma, as palavraschave (como livro, eles, semestre, dentre outras) revelam que o enfoque de Bernardo recai sobre os objetos de estudo dos grupos para os quais ele leciona e em como abordá-los (metodologia) em sua sala de aula. Seu discurso é centrado em sua prática docente e, o que se depreende é que a mesma é fruto de uma tentativa de reprodução de modelos por ele vivenciados ao longo de sua formação, porém adaptados à realidade profissional em que está atuando. Esta oposição - a adaptação de seu modelo ideal, baseado em sua experiência discente, ao seu contexto de trabalho - causa-lhe desconforto por perceberse obrigado a abrir mão do que gosta ou crê ser adequado a fim de tornar seu trabalho factível, como deixam claro algumas linhas de concordância geradas para livro.

${ }^{8}$ Neste trabalho foram apresentadas apenas algumas das muitas linhas de concordância encontradas para cada informante. As análises e a discussão apresentadas na atual e nas seções seguintes foram norteadas por todas as linhas geradas. Por impossibilidade de espaço, não poderemos divulgar os dados integralmente aqui. Contudo, para acesso aos mesmos: dani_menezes@oi.com.br. 
Com relação à Edna, o contraste entre sua experiência como professora de uma universidade particular e de uma universidade pública, como substituta, marca seu discurso. Ainda que a professora afirme que metodologicamente age de forma semelhante nos dois diferentes contextos, ela tece uma série de comparações ao longo da entrevista que são evidenciadas pelas linhas de concordância geradas para as palavras-chave aqui e a palavra que identificava a instituição em que a participante trabalhava.

No discurso de Fátima percebe-se que há uma tendência para evitar se colocar de maneira assertiva (o uso do acho, por exemplo) no tocante a aspectos metodológicos e sua visão sobre literatura, o que pode ser interpretado como uma tentativa de não se mostrar ditatorial em relação ao que pensa.

Em se tratando de Letícia, embora a questão metodológica apareça em seu discurso, esta possui uma relevância menor do que a preocupação institucional/curricular, como as ocorrências de graduação indicam. A professora demonstra um grau de envolvimento com a instituição que rompe as paredes da sala de aula. $\mathrm{O}$ foco de Letícia, revelado por suas linhas de concordância, portanto, recai sobre seu contexto único de atuação profissional.

A partir do discurso de Lúcio (universidades, privadas, distância), percebe-se que sua vasta experiência em termos de conhecimento do funcionamento do sistema de ensino superior supera os limites pré-estabelecidos da entrevista e faz com que os temas literatura e ensino sejam pontos de partida para a discussão de outras questões, como a problemática do ensino à distância e a dicotomia universidade pública $\mathrm{x}$ privada.

A análise das palavras-chave de Maria mostra que ela também direciona seu discurso a uma descrição de sua prática docente. A professora busca instituir um diálogo entre a literatura e outras mídias e gêneros numa perspectiva interacional / dialógica, como se percebe ao analisar as linhas de concordância geradas para balada, rock.

Com relação à professora Paula, as palavras-chave de seu discurso tendem a apresentar a professora como uma profissional que se preocupa com a literatura numa perspectiva institucional ou disciplinar (disciplina, disciplinas), que dá importância ao seu percurso acadêmico-profissional, mas que tende a desvalorizar o conhecimento prévio de seus alunos (conhecimento).

Observando as palavras-chave de Rogério (como arte, tinha, dia), foi possível perceber que ele parece não construir uma referência pessoal e nem se volta para os outros. $\mathrm{O}$ discurso de Rogério tende à teorização. Ele toma distanciamento das asserções que faz e demonstra menos preocupação com a alteridade do que os outros participantes. Há certa impessoalidade em seu discurso, uma maior abstração, diferindo-o de outros colaboradores do estudo, que tendem a discorrer acerca daquilo que fazem, de como fazem, narrando experiências pessoais.

Os achados para Vânia revelam forte preocupação metodológica. A maior parte das palavras-chave mostra a relevância que ela dá à maneira como seu trabalho é realizado (nome da instituição, obrigados etc.).

Nos dados, chama atenção o discurso de Raquel, para quem a única palavra-chave encontrada foi $d a$, que é uma palavra gramatical/funcional e não de conteúdo. Ao pesquisar no Corpus do Português' foi possível constatar que 'da' ocorre 8.009,16 vezes por 1

\footnotetext{
${ }^{9}$ www.corpusdoportugues.org
} 
MENEZES - Discurso sobre literaturas de língua inglesa: uma análise baseada...

milhão de palavras no registro oral e 5.350,50 vezes por 1 milhão de palavras no registro escrito. Disso, pode-se apenas constatar que $d a$ é muito mais recorrente na oralidade. Como entrevistas são exemplos de discurso oral, a fala de Raquel evidencia esse fato. As linhas de concordância geradas para a palavra não demonstram qualquer padrão. Sendo assim, parece não existir nada na fala de Raquel que a diferencie dos demais participantes da pesquisa. Uma hipótese para tentar explicar esta peculiaridade seria o fato de que o discurso de Raquel talvez seja mais equilibrado que os dos demais, contrabalanceando aquilo que os outros participantes potencializam.

\subsection{Dimensões sobre literatura e ensino de literatura}

Considerando que o assunto maior das falas dos docentes era literatura e ensino de literatura, percebemos que os participantes posicionaram-se de maneiras distintas: há aqueles cujas linhas de concordância geradas para as palavras-chave focalizam mais a questão do ensino, outros que priorizam a discussão por literatura e existem também os que equilibram seu discurso entre os dois temas. Esses posicionamentos podem ser compreendidos em termos de dimensões relativas aos seus interesses e identidade profissional.

Essas dimensões, ao invés de excludentes, são permeáveis, já que dificilmente o discurso de um participante se prende exclusivamente a apenas uma dimensão. Elas surgem da tentativa de sistematizar o discurso profissional dos participantes como um todo a partir da análise das linhas de concordância geradas para as palavras-chave de cada entrevista. Em outras palavras, as dimensões nada mais são do que uma tentativa de caracterizar o discurso global desses professores a partir do que há de específico em cada fala.

Acreditamos ser possível depreender cinco dimensões nos resultados encontrados. Quatro delas parecem estar mais focadas em aspectos acerca do ensino de literatura (institucional, metodológica, cognitiva e sócio-histórica), enquanto uma direciona-se especificamente à caracterização do objeto: ontológica. Portanto, é interessante constatar que a abordagem acerca do ensino de literatura destaca-se na fala dos participantes mais do que uma discussão teórica sobre literatura. A figura a seguir ilustra a distribuição dos professores em relação às cinco dimensões identificadas: 


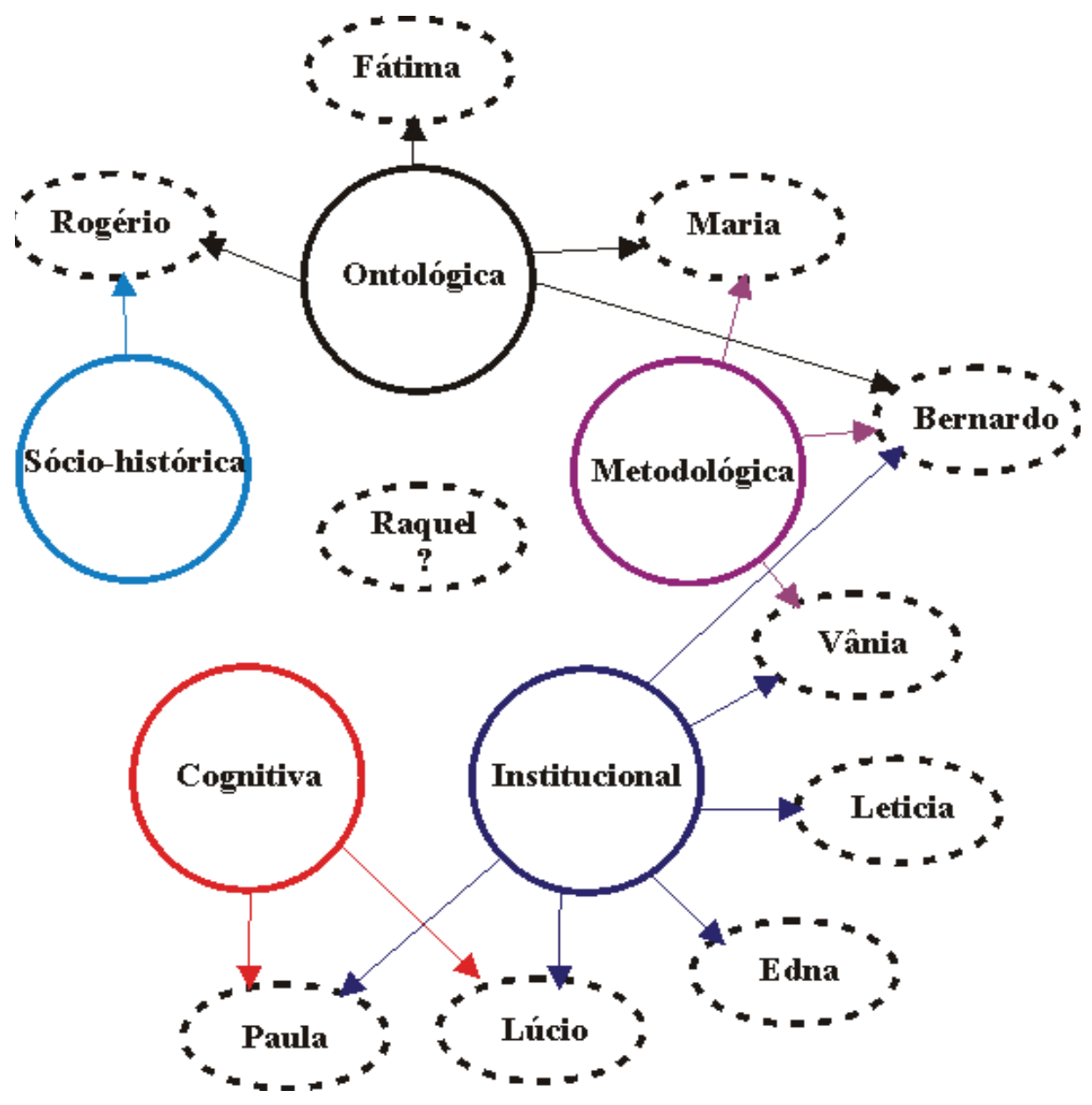

Figura 4 - Dimensões do discurso docente sobre literatura e seu ensino

A Figura 4, acima, apresenta a distribuição dos professores com relação às dimensões encontradas a partir da análise das linhas de concordância geradas para as palavras-chave e ilustra uma possível organização do discurso docente. Há, contudo um caso especial: o de Raquel. Por não terem sido encontradas palavras-chave cujas linhas de concordância pudessem caracterizar o seu discurso, a opção foi deixar seu nome solto no diagrama, indicando que, a nosso ver, Raquel talvez compartilhe das visões explicitadas por todas as dimensões.

As cinco dimensões estão representadas por cinco círculos, a saber: Ontológica, Metodológica, Institucional, Cognitiva e Sócio-histórica. Estas dimensões ligam-se, 
através de setas, aos nomes dos professores, cujos discursos, em graus variados, estão a elas relacionados.

As múltiplas setas, que saem de algumas dimensões e que apontam para mais de um participante, revelam aquilo que percebemos que sobressai em cada entrevista a partir da análise das linhas de concordância geradas para as palavras-chave. Por outro lado, o tracejado em torno dos nomes dos professores é descontínuo, para indicar que essas características, que pertencem ao discurso dos participantes como um todo, são permeáveis, independentemente das diferenças individuais. Isso significa dizer que, embora algumas dimensões predominem mais, a fala de cada professor pode ser influenciada pelas demais dimensões.

A seguir, oferecemos uma descrição geral de cada dimensão. A primeira a ser descrita é a Ontológica, que trata das conceituações de literatura. As demais, direcionadas ao ensino, estão dispostas em ordem de maior destaque nas falas:

a) Dimensão Ontológica: O foco aqui recai sobre a caracterização da literatura em si. Ora ela é apresentada como uma forma de arte, seja isso dito explícita ou implicitamente; ora faz-se referência ao impacto que a mesma provoca no leitor a partir do trabalho realizado pela linguagem; ora enfoca-se o potencial da literatura de refletir e registrar valores sóciohistórico-culturais etc. Esta dimensão parece permear mais o discurso de Bernardo, Fátima, Maria e Rogério.

b) Dimensão Institucional: O ensino de literatura é percebido como parte de outras atribuições dos docentes nas instituições em que lecionam. O próprio objeto de trabalho, literatura, é uma parte do conteúdo disciplinar lecionado e estipulado pela instituição. Assim, como o ensino de literatura é regulado por elementos externos à sala de aula, muitas decisões docentes precisam ser negociadas e, portanto, o professor possui autonomia limitada. Além disso, a natureza da instituição em que o professor está inserido é determinante para a forma como o mesmo avalia ou qualifica seu trabalho. Esta dimensão está mais representada nas falas de Bernardo, Edna, Letícia, Lúcio, Paula e Vânia.

c) Dimensão Metodológica: Essa dimensão, bastante forte em algumas falas, está relacionada ao fazer em sala de aula: técnicas ou estratégias utilizadas ou criadas, textos trabalhados / analisados, recursos empregados. Enfim, o foco aqui recai sobre as descrições das aulas. Bernardo, Maria e Vânia representam mais esta dimensão.

d) Dimensão Cognitiva: Relaciona-se às possibilidades cognitivas de professores e alunos no ensino de literatura. Percebe-se aqui a dificuldade para se realizar um trabalho efetivo por conta de um conhecimento prévio, por parte dos alunos, deficitário com relação a questões culturais relevantes aos conteúdos abordados ou à língua alvo. As falas de Lúcio e Paula evidenciam mais essa dimensão.

e) Dimensão Sócio-histórica: Busca-se contrastar passado e presente numa perspectiva de possibilidades de acesso a bens culturais e de construção do conhecimento. O resultado desta comparação é a constatação de que o passado propiciava melhores condições para o ensino e aprendizado de literatura que os dias atuais. Essa dimensão é mais enfocada por Rogério.

É importante enfatizar que essas dimensões tratam de uma tentativa de organizar a informação percebida nos dados. Isso evidencia a importância da subjetividade do pesquisador no processo de interpretação e organização dos resultados obtidos com o 
Trab. Ling. Aplic., Campinas, 50(1), Jan./Jun. 2011

auxílio das ferramentas computacionais utilizadas. Em outras palavras, recorrer a elementos tecnológicos não só facilita a prospecção dos dados, como também reafirma o papel essencial do sujeito na compreensão dos mesmos. Por essa razão, uma vez que os olhares sobre os fatos variam, ainda que uma diferente metodologia tivesse sido empregada, a possibilidade de outras percepções sobre os dados utilizados nesse estudo não seria excluída.

\section{CONSIDERAÇÕES FINAIS}

Além de corroborar o fato de que as escolhas lexicais dos falantes exercem diferentes funções em seu discurso (HALLIDAY, 1994), o tratamento oferecido aos dados sugere que o discurso dos participantes, como um todo, talvez possa ser caracterizado como estruturado em cinco dimensões permeáveis, que tendem a dar mais destaque ao ensino de literatura do que à discussão teórica sobre literatura. Isso quer dizer que, quando falam sobre literatura e ensino, os participantes enfatizam mais o ensino em si, ou seja, a prática, do que o objeto de trabalho - o fenômeno literário. Logo, a realidade em sala de aula e fatores a ela relacionados povoam o discurso dos participantes e mostram que as ocupações de um professor de literatura vão muito além do conhecimento teórico sobre literatura. Este profissional está imerso num todo pedagógico complexo que norteia suas escolhas sobre como proceder e faz com que as mesmas sejam refletidas em suas escolhas linguístico-semânticas.

Não podemos deixar de reconhecer que o interesse por uma discussão maior acerca de questões relativas ao ensino de literatura do que à literatura propriamente já era, em certa medida, um resultado esperado, uma vez que o roteiro seguido e a profissão dos entrevistados possibilitavam esse direcionamento. Contudo, o que encontramos sobre esse ensino aponta para diferentes perspectivas: as atitudes em sala de aula, a relação professor-aluno e o engajamento institucional, apenas para citar alguns, as quais variam de participante para participante. Assim, o que os dados desses docentes nos levam a pensar é que, entre eles, não há uma orientação metodológica capaz de direcionar seu trabalho ou uma visão consensual acerca do que seja ensinar literatura. Sendo assim, parece que os docentes realizam seu trabalho conforme suas próprias convicções, possivelmente repetindo modelos por eles já conhecidos. Acreditamos existir, portanto, uma necessidade latente de que as salas de aula de literaturas em inglês sejam investigadas, seguindo uma prática há bastante tempo frequente nas aulas de língua (cf. RAJAGOPALAN, 2001; JORDÃO, 2004; PAIVA, 2005; GIEVE e MILLER, 2006; MICCOLI, 2007).

Por fim, cabe reiterar que essas considerações se tornam possíveis graças ao tratamento oferecido aos dados. Ao utilizar a abordagem de corpus para olhar de forma empírica textos reais, ou seja, a língua em uso (OLIVEIRA, 2009), percebemos que questões de cunho social, político e ideológico são evidenciadas no tecido linguístico (FAIRCLOUGH, 2001; HALLIDAY e HASAN, 1989; HALLIDAY, 1994). Esse tratamento, que não objetiva contemplar a complexidade de cada fala, mas chama atenção para aquilo que diferencia uma das demais, contribui para a construção de uma ideia geral acerca do conteúdo do discurso dos participantes como um todo e assegura ao pesquisador papel essencial na interpretação dos resultados. 


\section{REFERÊNCIAS BIBLIOGRÁFICAS}

BAKER, P. (2004). Querying keywords: questions of difference, frequency, and sense in keywords analysis. In: Journal of English Linguistics. v. 32, n. 4, p. 346-359.

BAKHTIN, M. (1930). Marxismo e Filosofia da Linguagem. (tradução de Michel Lahud e Yara Frateschi Vieira). São Paulo: Editora Hucitec, 1979. (1979). Adendo - Os gêneros do discurso. In: Estética da Criação Verbal. (tradução de Paulo Bezerra). São Paulo: Martins Fontes, 2006.

BARLOW, M. (1996). Corpora for Theory and Practice. In: International Journal of Corpus Linguistics. v. 1, n. 1, John Benjamins Publishing Co., p. 1-37.

BERBER SARDinHA, B. (2004). Linguística de Corpus. Manole: São Paulo.

BIBER, D., CONRAD, S. \& REPPEN, R. (1998). Corpus Linguistics: Investigating Language Structure and Use. Cambridge: CUP.

CHOULIARAKI, L.; FAIRCLOUGH, N. (2001). Chapter 8: Critical Discourse Analysis and Linguistics. In: Discourse in Late Modernity: Rethinking Critical Discourse Analysis. Edinburgh: Edinburgh Univesity Press, p. 139-155.

FAIRCLOUGH, N. (2001). Discurso e mudança social. Brasília: Editora Universidade de Brasília.

GIEVE, S.; MILLER, I. K. (ed.). (2006). Understanding the language classroom. Hampshire, United Kingdom: Palgrave Macmillan, p. 18-46.

GONÇALVES, L. (2008). Linguística de Corpus e análise literária: o que revelam as palavras-chave. In: TAGNIN, S.; VALE, O. (orgs.) Avanços da Linguística de Corpus no Brasil. São Paulo: Humanitas, p. $387-405$

GRIGOLETTO, M. (2001). Língua e identidade: Representações da língua estrangeira no discurso de futuros professores de língua inglesa. In: CARMAGNANI, A. M. G.; GRIGOLETTO, M. (org.). Inglês como língua estrangeira: identidade, práticas e textualidade. São Paulo: Humanitas / FFLCH / USP, p. 135152.

HALLIDAY, M. A. K. (1994). An introduction to functional grammar ( $2^{\text {nd }}$ ed.). London: Arnold.

HALLIDAY, M. A. K.; HASAN. (1989). Language, Context, and Text: Aspects of Language in a Social-semiotic Perspective. Oxford: OUP.

HUNSTON, S. (2005). Corpora in Applied Linguistics. Cambridge: Cambridge University Press.

JORDÃO, C. M. (2004). A língua inglesa como 'commodity': direito ou dever de todos? In: ROMANOWSKY, J.; MARTINS, P.; JUNQUEIRA, S. (org.). Conhecimento Local e Conhecimento Universal. 1 ed. Curitiba: Champagnat, v. 3, p. 287-296.

JORGE, M. L. S. (2001). Prática de Ensino de Inglês: o estágio como experiência integradora da teoria, reflexão e prática. In: CARMAGNANI, A. M. G.; GRIGOLETTO, M. (org.). Inglês como língua estrangeira: identidade, práticas e textualidade. São Paulo: Humanitas / FFLCH / USP, p. 499-508.

KEYS, K. J. (2001). First language influence on spoken English of Brazilian students of EFL: preliminary results of a longitudinal study. In: CARMAGNANI, A. M. G.; GRIGOLETTO, M. (org.). Inglês como língua estrangeira: identidade, práticas e textualidade. São Paulo: Humanitas / FFLCH / USP, p. 439-448. 
Trab. Ling. Aplic., Campinas, 50(1), Jan./Jun. 2011

LÉVINAS, E. ( [1972). Humanismo do outro homem. Petrópolis, RJ: Vozes, 1993.

LÜDKE, M.; ANDRÉ, M. E. D. A. (2001). Pesquisa em Educação: Abordagens Qualitativas. São Paulo: EPU.

MENEZES, D. A.; ZYNGIER, S. (2009). Reflexões sobre o ensino de literaturas de língua inglesa no Brasil: um estudo diacrônico. In: ZYNGIER, S.; VIANA, V.; JANDRE, J. (org.) Linguagem, Criatividade \& Ensino: Abordagens Empíricas e Interdisciplinares. Rio de Janeiro: Publit Soluções Editoriais, p. 275-294.

MICCOLI, L. (2007). Experiências de professores no ensino da língua inglesa. In: Linguagem \& Ensino. v. 10, n.1, jan./jul., p. 47-86.

OLIVEIRA, L. P. (2009). Linguística de Corpus: teoria, interfaces e aplicações. In: Matraga. v. 16, n. 24, jan/ jun., p. 48-76.

PAIVA, V. L. M. O. (2005). Refletindo sobre estilos, inteligências múltiplas e estratégias de aprendizagem. In: PAIVA,V. M. O. (org.). Práticas de ensino e aprendizagem de inglês com foco na autonomia. Belo Horizonte: Faculdade de Letras da UFMG, p. 11-30.

RAJAGOPALAN, K. (2001a). Transdisciplinarity in the teaching of English as a foreign language. In: CARMAGNANI, A. M. G.; GRIGOLETTO, M. (org.). Inglês como língua estrangeira: identidade, práticas e textualidade. São Paulo: Humanitas/FFLCH/USP, p. 23-28.

, (2001b). ELT classroom as an arena for identity clashes. In: CARMAGNANI, A. M. G.; GRIGOLETTO, M. (org.). Inglês como língua estrangeira: identidade, práticas e textualidade. São Paulo: Humanitas / FFLCH / USP, p. 79-90.

RICHARDS, J. C.; RODGERS, T. S. (2001) Approaches and Methods in Language Teaching. Cambridge UK: Cambridge University Press.

ROLLEMBERG, A. T. V. M. (2008). Dedicação, frustração, sucesso, dúvidas - construção de identidades profissionais nas narrativas de professores de inglês. Tese de Doutorado. Pontifícia Universidade Católica do Rio de Janeiro.

SÁ CAMPOS, L. M. H. (1987). A licenciatura em Letras - Deficiências e potencialidades. Pespectiva Sóciohistórico-pedagógica. Tese de Doutorado. Universidade Federal do Rio de Janeiro - Centro de Filosofia e Ciências Humanas - Faculdadade de Educação.

SCOTT, M. (1999). WordSmith Tools, versão 3.0. Oxford: Oxford University Press.

TAGNIN, S.; TEIXEIRA, E. (2004). British vs. American English, Brazilian vs. European Portuguese: how close or how far apart? - a corpus-driven study. In: LEWANDOWSKA-TOMASZCZYK, B. (ed.) Practical applications in language and computers (PALC 2003). Frankfurt am Main: Peter Lang, p. 193-208.

THOMPSON, G; HUNSTON, S. (2006). System and corpus: two traditions with a common ground. In: THOMPSON, G; HUNSTON, S. (eds.) System and Corpus: exploring connections. London: Equinox Publishing Ltd., p. 1-14.

TOGNINI-BONELLI, E. (2001). Corpus linguistics at work. Amsterdam: John Benjamins.

TRAPPES-LOMAX, H. (2004). Discourse analysis. In: DAVIES, A.; ELDER, C. (eds.). The handbook of applied linguistics. Malden, MA; Blackwell, p. 133-164.

VIANA, V. P. (2008). Verbos modais em contraste: análise de corpus da escrita de universitários em inglês. Rio de Janeiro. 247fl. Dissertação de Mestrado - Departamento de Letras, Pontifícia Universidade Católica do Rio de Janeiro.

VIANA, V.; TAGNIN, S. (2011). Corpora no ensino de línguas estrangeiras. São Paulo: Hub Editorial. 
MENEZES - Discurso sobre literaturas de língua inglesa: uma análise baseada...

ZYNGIER, S. (2003). A pedagogia crítica, a estilística e o ensino da literaturas de língua inglesa. In: STEVENS, C. M. T e CUNHA, J. C. Caminhos e colheita: ensino e pesquisa na área de inglês no Brasil. Brasília: Editora Universidade de Brasília, p. 107-126.

Recebido: $15 / 08 / 2010$

Aceito: $12 / 04 / 2011$ 